\title{
Participação popular no processo de planejamento urbano: a universidade como "decodificadora" de um sistema de muitos códigos
}

\author{
Popular participation in the process of urban planning: the \\ university as "decoder" of a system of many codes
}

Rafaela Vieira ${ }^{[a]}$, Luciana Noronha Pereira ${ }^{[b]}$, Francisco Antônio dos Anjos ${ }^{[c]}$, Taline Schroeder ${ }^{[d]}$

[a] Arquiteta e Urbanista, doutora em Geografia pela Universidade Federal de Santa Catarina (UFSC), professora do Curso de Arquitetura e Urbanismo e do Mestrado em Turismo e Hotelaria da Universidade do Vale do Itajaí (Univali), Balneário Camboriú, SC - Brasil, e-mail: rafaela@univali.br

[b] Arquiteta e Urbanista, mestre em Turismo e Hotelaria pela Universidade do Vale do Itajaí (Univali), professora do Curso de Arquitetura e Urbanismo da mesma instituição, Balneário Camboriú, SC - Brasil, e-mail: lunope@gmail.com

[c] Geógrafo, doutor em Engenharia de Produção pela Universidade Federal de Santa Catarina (UFSC), professor do Curso de Arquitetura e Urbanismo e do Mestrado em Turismo e Hotelaria da Universidade do Vale do Itajaí (Univali), Balneário Camboriú, SC - Brasil, e-mail: fsanjos@terra.com.br

[d] Graduanda em Arquitetura e Urbanismo na Universidade do Vale do Itajaí (Univali), Balneário Camboriú, SC - Brasil, e-mail: talineschroeder@gmail.com

\section{Resumo}

O objetivo deste artigo foi refletir sobre a participação da população no processo de revisão do Plano Diretor do município de Camboriú, em Santa Catarina. A análise leva em consideração a experiência vivenciada por alunos e professores do curso de Arquitetura e Urbanismo da Universidade do Vale do Itajaí (Univali) durante a realização do projeto de extensão e filantropia intitulado "Assessoria aos Gestores Públicos no Processo de Revisão do Plano Diretor de Desenvolvimento Territorial de Camboriú/SC", nos anos de 2011 e 2012. As técnicas utilizadas para o desenvolvimento da referida assessoria foram pesquisa bibliográfica, documental (com dados primários e secundários) e de campo, com observação direta intensiva. A construção de uma democracia participativa no município de Camboriú caracteriza-se pela busca de um processo de participação popular representativa e deliberativa. Entende-se que somente mediante capacitação popular, ação esta que deve ser exercida em parceria com a Universidade, poderá haver participação plena dos cidadãos, em busca de uma democracia participativa emancipatória.

Palavras-chave: Participação popular. Plano diretor. Planejamento urbano. Democracia participativa.

\section{Abstract}

The aim was to reflect on people's participation in the review process of the Master Plan of the city of Camboriu, Santa Catarina. The analysis takes into account the lived experience of students and faculty from 
the Architecture and Urbanism of the University of Vale do Itajai (UNIVALI) during the course of the extension project and philanthropy titled "Advice to Public Managers in the Plan Review Process Director Territorial Development of Camboriu / SC", in the years 2011 and 2012. The techniques used for the development of that advice were literature, documentary (with primary and secondary data) and field with intensive direct observation. The construction of a participatory democracy in the city of Camboriu is characterized by a process of popular participation and deliberative representative. It is understood that only through training popular action that should be pursued in partnership with the university, there may be full participation of citizens in search of an emancipatory participatory democracy.

Keywords: Popular participation. Master plan. Urban planning. Participatory democracy.

\section{Introdução}

O Estatuto da Cidade, Lei Federal n. 10.257/2001 (BRASIL, 2001), prevê vários instrumentos da política urbana, dentre eles o plano diretor, que deverá englobar a totalidade do território municipal. 0 mesmo é obrigatório para os municípios com mais de 20 mil habitantes, integrantes de regiões metropolitanas e aglomerações urbanas, integrantes de áreas de especial interesse turístico, onde o poder público municipal pretenda utilizar os instrumentos previstos na Constituição Federal, inseridos na área de influência de empreendimentos ou atividades com significativo impacto ambiental de âmbito regional ou nacional e incluídos no cadastro nacional de municípios com áreas suscetíveis à ocorrência de deslizamentos de grande impacto, inundações bruscas ou processos geológicos ou hidrológicos correlatos.

A referida base legal exige que a construção dos planos diretores seja feita com efetiva participação popular, indicando alguns instrumentos para garantir essa gestão democrática. Entretanto, a efetividade dessa participação muitas vezes é prejudicada pela atuação dos diversos agentes envolvidos no processo. Esse prejuízo se apresenta pelo desconhecimento de aspectos legais do que pode ou não ser entendido como processo participativo; pela tentativa de evitar conflitos e, assim, eliminar a possibilidade de discussão e consenso, em favor de interesses de grupos específicos; ou ainda, pela presença pouco representativa da população que, por vezes, não se sente detentora instrumentos e conhecimentos para as discussões, ou ainda, não acredita que o processo de mudança possa ser desencadeado por sua participação; recursos financeiros e de tempo limitados; dentre outros problemas já levantados por diversos autores em experiências pelo Brasil pós-Estatuto da Cidade (BOSCHI, 1999; BRAGA, 1995; SILVA, 2001; VALLA, 1998).

0 presente artigo refere-se a experiência vivenciada por alunos e professores do curso de Arquitetura e Urbanismo da Universidade do Vale do Itajaí (Univali) durante os anos de 2011 e 2012, na realização do projeto de extensão e filantropia intitulado "Assessoria aos Gestores Públicos no Processo de Revisão do Plano Diretor de Desenvolvimento Territorial de Camboriú (SC)".

As técnicas utilizadas para o desenvolvimento da referida assessoria foram pesquisa bibliográfica (com acesso as bases de dados SciELO e EBSCO), documental (com dados primários e secundários) e de campo, com observação direta intensiva.

A escolha do município estudado, Camboriú, no Estado de Santa Catarina (Figura 1), ocorreu, pois se enquadra dentre aqueles com obrigatoriedade de possuir plano diretor, especialmente por ter população com mais de 20 mil habitantes no ano de 2006 (prazo limite estabelecido pelo Estatuto da Cidade para elaboração dos planos diretores). Segundo o Censo Demográfico do IBGE (2010), a população de Camboriú era de 62.361 habitantes, apresentando um crescimento populacional de $4,17 \%$ ao ano, ao longo da primeira década de 2000.

0 artigo estrutura-se em três partes. Inicialmente, aborda-se discussões teóricas sobre participação social e planejamento urbano; na sequência, apresenta-se a experiência vivenciada no município estudado; finalizando-se com reflexões e considerações finais. 


\section{Considerações teóricas sobre participação social no processo de planejamento urbano}

Politeia, palavra grega que se vincula a polis (cidade), representava uma forma de governo exercida pelos cidadãos, tendo como ponto de partida a igualdade social de acordo com Aristóteles (2005). 0 termo política é derivado dessa assembleia de cidadãos como parte do processo de governo, evidenciado desde a Grécia Antiga.

Ao longo da história, tal participação exercida pelos cidadãos no processo de governo obteve expressões distintas. 0 processo de construção da cidade industrial vincula-se a acentuação de uma falsa política, caracterizada pelo individualismo e patrimonialismo, cujas origens remetem ao Renascimento, quando as classes emergentes perceberam que seu envolvimento na política poderia lhes proporcionar vantagens na seguridade de seus patrimônios. Nesse contexto, a própria cidade sofre as consequências, de modo formal e prático, em função dessa luta individualista do direito à cidade, com políticas centralizadoras, nas quais os interesses particulares prevalecem, em detrimento dos públicos, expressando-se na segregação socioespacial (OLIVEIRA FILHO, 2009).

Na década de 1930, os ideais do modernismo expressam-se em uma tentativa de busca por uma sociedade mais igualitária. Conforme Holston (1993), na redução da discriminação arquitetônica e urbanística há uma consequente redução das discriminações sociais, visando propiciar essa igualdade. Isso é anunciado na estética arquitetônica, mas também na forma de enxergar a cidade e de projetá-la.

A Carta de Atenas ${ }^{1}$, documento resultante do IV Congresso Internacional da Arquitetura Moderna (CIAM), de 1933, traça os princípios desse Urbanismo Moderno. Tinha características inovadoras, pois analisava e propunha que a cidade fosse organizada e projetada segundo as necessidades humanas universais do século XX, por meio de quatro (quatro) funções: habitar, trabalhar, locomover-se e cultivar o corpo e o espírito (CHOAY, 2000). Segundo Oliveira Filho (2009), este conceito recebeu fácil aceitação pelo Estado, especialmente no caso brasileiro, graças ao intenso conteúdo técnico que ganhou alcance mundial, havendo uma renovação jurídica e política pela forma inovadora destes projetos, que respondia à racionalidade dominante naquele momento histórico.

Para Souza (1998), todas essas propostas inovadoras continham uma fundamentação e organização coerente, mas as vertentes urbanísticas estavam muito engessadas em uma visão marcadamente tecnocrática, na qual a gestão continuou autoritária, sendo esta somada à ciência e tecnologia industrial. Era excluído o que não fazia parte dessa linguagem, favorecendo que planejamento não incluísse características participativas.

No Brasil, importante expoente mundial do Modernismo, essa vertente se expressa em um período que o interesse do país voltou-se ao ambiente urbano (não mais rural), havendo forte concordância com as políticas nacionais (DEL RIO; GALLO, 2000).

Esses projetos reformadores eram regidos por meio de planos, zoneamentos, leis de ocupação e ordenação do solo e que, por isso, tinham um respaldo jurídico complexo. A concordância desses projetos com a política resultou na supervalorização dos planos diretores, sem o entendimento do que esse instrumento realmente era pela maior parte da população, bem como pelos técnicos e gestores municipais. Para Villaça (1998), são planos que ficaram sob regimento dos interesses imobiliários, que defendiam limitá-lo às políticas, objetivos e diretrizes gerais, sem ter neles dispositivos autoaplicáveis. Isso fez com que não houvesse comprometimento $\mathrm{e}$ o plano servisse como mais um documento de "gaveta" e não de prática: "O plano diretor acaba assim, por se tornar aquele plano que define orientações sobre como deverá ser o plano quando ele vier a ser feito" (VILLAÇA, 1998, p. 8). Esse descomprometimento gerou uma inevitável desmobilização da população na sua representatividade política por falta de resultados práticos.

O conjunto formado pelas leis de zoneamento, parcelamento do solo e detalhados códigos de edificações compunham um instrumento autoaplicável

\footnotetext{
1 Em 1998, o Conselho Europeu de Urbanistas (CEU) propôs uma nova Carta de Atenas, com o foco na cidade contemporânea. Essa carta sofreria revisão no intervalo de quatro anos, sendo a primeira em 2003. Com esses estudos, novas funções foram incluídas, porém, também não são limitadas (BERNARDI, 2006), em virtude do grande desenvolvimento e transformação da sociedade.
} 
(VILLAÇA, 1998), mas que, na prática brasileira, não faziam parte do plano diretor, constituindo-se em suas leis complementares. Para Maricato (2000), eles eram desenvolvidos com rigor, mas acabavam desconsiderando condições de ilegalidade, comuns à realidade da maior parte da população brasileira, especialmente no que diz respeito à moradia. Isso demonstra uma legislação de exclusão, segundo afirma Back (2004), a qual projeta rigorosamente uma ocupação legal e ideal, mas ignora uma ocupação real e ilegal.

Tal insatisfação em relação à gestão urbana, fez com que na década de 1960 iniciassem as primeiras críticas à qualidade dos espaços urbanos, apesar da repreensão de um governo ditatorial militar brasileiro. Mesmo com o golpe militar de 1964, houve fortalecimento desses movimentos, que durante o fim da década de 1970 e início da década de 1980 fomentaram um debate a respeito de um novo conceito de planejamento urbano que pudesse incluir a participação popular (OLIVEIRA FILHO, 2009).

Os anos 1990, segundo Rolnik (2006) foram marcados por muitos avanços no direito à moradia e em seu fortalecimento jurídico, mas também no direito à cidade, com debates partindo da sociedade civil acerca do papel dos cidadãos na gestão, com a reestruturação de um movimento pela reforma urbana e pela constituição de um fórum. Esse movimento se fortaleceu, havendo a participação popular em orçamentos, Conselhos gestores e programas autogestionados de forma efetiva em diversos municípios, não restrita ao campo parlamentar.

No mesmo período, nos países industrializados, é possível observar que coexistem diferentes tipos/ formatos/linhas de planejamento, dentre os quais o Planejamento Colaborativo (HEALEY, 1997; IINNES; BOOHER, 1999 apud RANDOLPH, 2007), desenvolvido a partir da teoria de Habermas sobre a ação comunicativa e das discussões da década de 80 acerca do planejamento comunicativo. Para Torres (2009, p. 580), esse modelo de planejamento consiste em "um modo de criar relações e de compartilhar conhecimentos entre os participantes com o objetivo de criar capacidade para confrontar a situações problemáticas" em busca de diálogo a partir do qual os conflitos poderiam ser minimizados em busca de uma solução comum e compartilhada.

A difusão deste modelo pode ser verificado a partir da inclusão de um modelo de construção através da participação, conforme o Estatuto da Cidade exige, já após o ano 2000 , tendo como princípio a ideia de rompimento com as estruturas de poder vigente produtoras das lógicas de segregação socioespacial (KLINK, 2011). Dentre suas limitações identificadas e discutidas por outros autores (MELUCCI, 1985; FAINSTEIN, 2000 apud RANDOLPH, 2007), podem ser citadas seu caráter iminentemente simbólico da colaboração (RANDOLPH, 2007).

O new urbanism surgido nos anos 90, nesse sentido, apresenta-se em oposição ao modelo anterior, haja vista a valorização que confere "toda a ênfase aos processos materiais de intervenção no meio urbano" (RANDOLPH, 2007, p. 2). Randolph (2007) também cita um terceiro alinhamento chamado de cidade justa, caracteristicamente mais comprometido com a economia política.

Todo esse debate resultou na inclusão dos artigos 182 e 183, que tratam da política urbana, na Constituição Federal de 1988, com o objetivo de "ordenar o pleno desenvolvimento das funções sociais da cidade" (BRASIL, 1988). Além disso, a Constituição afirmou o papel dos municípios como atores principais da política de desenvolvimento e gestão urbana e elegeu o plano diretor como seu principal instrumento para o desenvolvimento e expansão urbana, vinculando-o à função social da propriedade (SANTOS Jr.; SILVA; SANT'ANA, 2011).

Todo o descrédito para com a legislação e planos diretores "não aplicáveis" deveria chegar ao fim com a aprovação do Estatuto da Cidade, Lei Federal n. 10.257/2001 (BRASIL, 2001), que regulamentou os dispositivos constitucionais. Nele, foram afirmadas novas diretrizes, princípios e principalmente instrumentos, destinados à promoção do direito à cidade e à gestão democrática, na qual a população teria voz e vez.

\section{O Estatuto da Cidade e a construção da participação social no Planejamento Urbano}

A Constituição Federal de 1988 já continha a obrigatoriedade de elaboração do plano diretor, em seu artigo 41, para cidades com mais de 20 mil habitantes. Contudo, sua regulamentação só ocorreu com o Estatuto da Cidade em 2001, o qual traz importantes instrumentos de política urbana para promoção da função social da propriedade, 
participação popular e equilíbrio ambiental, entre outros aspectos. Enfatiza os instrumentos da política urbana, corroborando com a Constituição Federal, objetivando "ordenar o pleno desenvolvimento das funções sociais da cidade e da propriedade urbana" (BRASIL, 2001).

A função social da propriedade e da cidade, por estar vinculada a um projeto de uma cidade mais igualitária, tem uma destinação social, na qual o interesse comum sobrepõe-se ao individual. Segundo o Fórum Nacional da Reforma Urbana (2012), a função social da propriedade e da cidade se constitui no uso socialmente justo do espaço urbano, visando à apropriação do território com base em parâmetros de justiça social.

Para que haja efetividade na aplicação desses instrumentos da política urbana visando o desenvolvimento das funções sociais da cidade e da propriedade em prol do bem coletivo, orienta-se a vinculação destes instrumentos aos Planos Diretores Municipais. Diferente disso, o que tem sido observado em vários casos é que os planos diretores limitaram-se a reproduzir o texto do Estatuto da Cidade. Segundo Freire, Cymbalista e Nakahima (2009), esse foi o caso do município de Sorocaba, em São Paulo, no qual se pôde identificar a superficialidade na aplicação dos instrumentos a partir de entrevistas realizadas aos técnicos do poder público, que agiram somente em resposta às exigências do Estatuto da Cidade. 0 resultado, segundo os referidos autores, constituiu-se de decisões sem amadurecimento e falta de entendimento dos atores sociais em relação ao significado dos instrumentos e suas formas de utilização.

De acordo com Santos Jr. e Montandon (2011), há casos em que os planos apenas incorporaram trechos do Estatuto. Outros até incorporam os instrumentos, mas sem relacioná-lo ao território e a sua capacidade de gestão. Outros incorporam partes do Estatuto, mas sem estabelecer relação alguma com seu plano urbanístico. Ao contrário dessas experiências malsucedidas, há exemplos em que há diálogo entre o plano e os instrumentos, buscando o cumprimento real da função social da propriedade, aliada aos vários setores da sociedade.

É necessário o entendimento da capacidade de gestão do município, para que haja real vinculação do plano diretor com os instrumentos do Estatuto da Cidade.
Por isso, em seu capítulo IV o Estatuto da Cidade exige que os planos diretores tenham efetiva participação popular, indicando quatro instrumentos para garantir essa gestão democrática: os órgãos colegiados de política urbana nos níveis nacional, estadual e municipal; debates, audiências e consultas públicas; conferências sobre assuntos de interesse urbano nos níveis nacional, estadual e municipal; e iniciativa popular de projeto de lei e de planos, programas e projetos de desenvolvimento urbano (BRASIL, 2001).

Há a nomeação desses instrumentos para se determinar como se daria esta participação popular e mostrar como eles, em suas funções variadas e de forma articulada em um mesmo objetivo, trabalhariam em melhorias para os municípios, alcançando realmente o propósito democrático na gestão urbana tão defendido no Estatuto da Cidade (MUNIZ; FERREIRA; MIGLIORINI, 2008). Assim, conforme nos afirmam Limonad e Barbosa (2003, p. 4):

No âmbito do "Estatuto da Cidade" o Estado é encarado como interventor, ordenador e controlador, neste sentido esta lei propõe uma articulação entre os três níveis de poder, ao mesmo tempo em que deixa definições e especificações a cargo do poder local, e abre uma perspectiva de participação para a população e grupos organizados.

Como forma de auxílio às cidades foi criado, por meio do Decreto Federal n. 4.665/2003 (BRASIL, 2003), o Ministério das Cidades, órgão da administração federal, com a função de "incentivar a construção de uma nova cultura de planejamento urbano no país, fortalecendo o apoio ao planejamento urbano dos municípios" (SANTOS Jr.; SILVA; SANT'ANA, 2011, p. 15).

O Decreto Federal n. 4.665/2003, que aprovou, dentre outras providências, a estrutura regimental e organizacional do Ministério das Cidades e cita, dentre outros órgãos colegiados de política urbana, o Conselho da Cidade, em âmbito federal. Foi com o Ministério que um órgão federal de política urbana tornou-se realmente possível. Com o Conselho das Cidades a gestão democrática está presente em todas as ações promovidas pelo Ministério das Cidades, pois ele "tem participado ativamente dos avanços e debates sobre a política urbana, contribuindo sobremaneira para o fortalecimento 
da gestão democrática nos estados e municípios" (NEGROMONTE, 2011, p. 11).

Seu papel tem sido relevante nos estados e municípios, graças à representatividade desses níveis na própria composição do Conselho. São 17 representantes do poder público federal, representados dos demais ministérios; 9 do poder público estadual, através de uniões estaduais, sendo todos os estados distribuídos em titulares, suplentes e observadores; e 12 do poder público municipal; através de frentes nacionais de prefeitos e vereadores ou confederação nacional de municípios. Além destes, há 22 representantes de movimentos populares, 8 de trabalhadores, 8 de empresários, 6 de entidades profissionais, acadêmicas ou de pesquisa e 4 de ongs (MINISTÉRIO DAS CIDADES, 2012).

Tudo isso propicia o contato entre os órgãos colegiados de política urbana em outros níveis e possibilita a ocorrência de outros instrumentos de participação popular citados no texto do Estatuto, como: debates, audiências e consultas públicas; conferências sobre assuntos de interesse urbano em diversos níveis, sendo ele estadual ou municipal. Segundo o Decreto Federal n. 5.790 de 2006 (BRASIL, 2006), é função do Conselho da Cidade "a promoção de cooperações, incentivos e parcerias com Conselhos Gestores afetos à política de desenvolvimento urbano nos níveis municipais, regionais, estaduais e do Distrito Federal".

Desde então, o Ministério das Cidades vem apoiando os municípios para a elaboração dos Planos Diretores, "tanto por meio de recursos próprios, quanto por meio de parcerias institucionais, via apoio financeiro direcionado à assistência técnica e por meio de processos de capacitação" (SANTOS Jr.; MONTANDON, 2011, p. 19).

Todo esse processo de preocupação com a participação popular na gestão política representou na história da gestão urbana brasileira, uma proposta inovadora, que se denominou Gestão Social, por sua forte postura inclusiva e de descentralização administrativa (ULTRAMARI; FIRKOWSKI, 2012).

Mesmo com toda essa proposta inovadora e esse respaldo jurídico e institucional em busca de uma participação popular em todas as etapas do desenvolvimento desses Planos Diretores, tendo a intenção de proporcionar cidades socialmente mais justas, essa participação ainda se encontra sob o "comando" do Estado, que rege quando e onde vai acontecer essa participação. Segundo Flávio Villaça (2005, p. 50),

poder-se-ia entender "Participação Popular" como o conjunto de pressões que "a população" exerce sobre o poder político, por ocasião da tomada de importantes decisões de interesse coletivo. Numa concepção mais restrita, essa participação tem-se identificado no Brasil com a participação da "população" em debates políticos oficiais, convocados tanto pelo Legislativo como pelo Executivo.

Diante dessa afirmação, identifica-se um problema de gestão de nossas cidades, muitas vezes excludente, mas com o nome de "participativo", devido à obrigatoriedade legal de participação. Essa problemática decorre de um problema maior, que é o próprio histórico de formação do sistema democrático participativo atual.

\section{Democracia participativa no processo de planejamento urbano}

Imerso nos modelos de democracia, um longo caminho teórico foi percorrido até chegar ao conceito da teoria participativa. Segundo Oliveira Filho (2009), a democracia liberal passou por concepções elitistas, representadas por Joseph Shumpeter, na década de 1940, e Max Weber, na década de 1960, em que a democracia era entendida como o modo de selecionar pessoas para tomar decisões coletivas, sendo a prática de escolher líderes em potencial. Também passou por concepções pluralistas ou poliárquicas, representada por Dahl na década de 1950, que observa a democracia como forma de disputa entre elites, como negócio. Enfim, em 1977, a concepção participativa surge a partir dos movimentos estudantis de 1960, com a proposta de Macpherson.

Para MacPherson (1977), é necessário um sistema representativo, pois não é possível um sistema direto em meio a uma sociedade tão complexa. Contudo, deve-se atentar para uma questão central da democracia participativa: a maneira de atingi-la e não seu funcionamento. 0 referido autor afirma que a política não é concorrencial e excludente, pois entende a participação com um sentido mais forte de comunidade, que promove uma horizontalidade nas decisões políticas. 
No âmbito da concepção participativa de democracia existe a noção de política deliberativa e a emancipatória ou inclusiva. A teoria deliberativa de participação, desenvolvida por Jürgen Habermas em 1983, é marcada pela representatividade e na busca do equilíbrio entre interesses divergentes e não predeterminados (HABERMAS, 2002).

A separação entre o aparato estatal e a sociedade, cuja eliminação o conceito liberal entende não ser possível, utiliza de "procedimentos comunicacionais" para tal fim. Dessa forma, "a opinião pública, transformada em poder comunicativo, segundo procedimentos democráticos, não pode 'dominar', mas apenas direcionar o uso do poder administrativo para determinados canais e ter o 'poder' de programar o exercício do poder político" (HABERMAS, 2002, p. 282). Procura-se propiciar isso por meio dos consensos na resolução de questões em que haja desacordo, devendo haver discussão em diversos formatos, principalmente através de audiências públicas e Conselhos Gestores.

Isso caracteriza uma tentativa intensa de igualdade de opinião, partindo do princípio que o cidadão é o agente e quem determina a agenda. Contudo, isso não se aplica aos Conselhos atuantes no Brasil e a crítica de Villaça (2005) em relação a quem está no "comando" dessa participação ainda permanece.
Além disso, é mais representativa (os representantes são escolhidos) que deliberativa.

A noção emancipatória estabelece uma crítica ao modelo deliberativo, por se levar em conta as diversas situações políticas, sociais e culturais. Santos $(2002,2006)$ usa o termo para identificar uma democracia de emancipação política e de transformação social.

\section{A experiência da Universidade do Vale do ltajaí no processo de elaboração e revisão do plano diretor de Camboriú}

A elaboração do primeiro Plano Diretor de Desenvolvimento Territorial de Camboriú (Figura 1), Lei Complementar n. 010/2007 (CAMBORIÚ, 2007), ocorreu durante os anos de 2006 e 2007. Esse processo contou com a assessoria de professores da Universidade do Vale do Itajaí, autores do presente artigo, cujo trabalho foi financiado pelo CNPq, por meio de edital de chamada pública de projetos, realizada em parceria com o Ministério das Cidades.

Durante a elaboração do referido plano diretor, pôde-se constatar a atratividade populacional do município de Camboriú, motivado pela busca de local de moradia e pelo avanço da economia

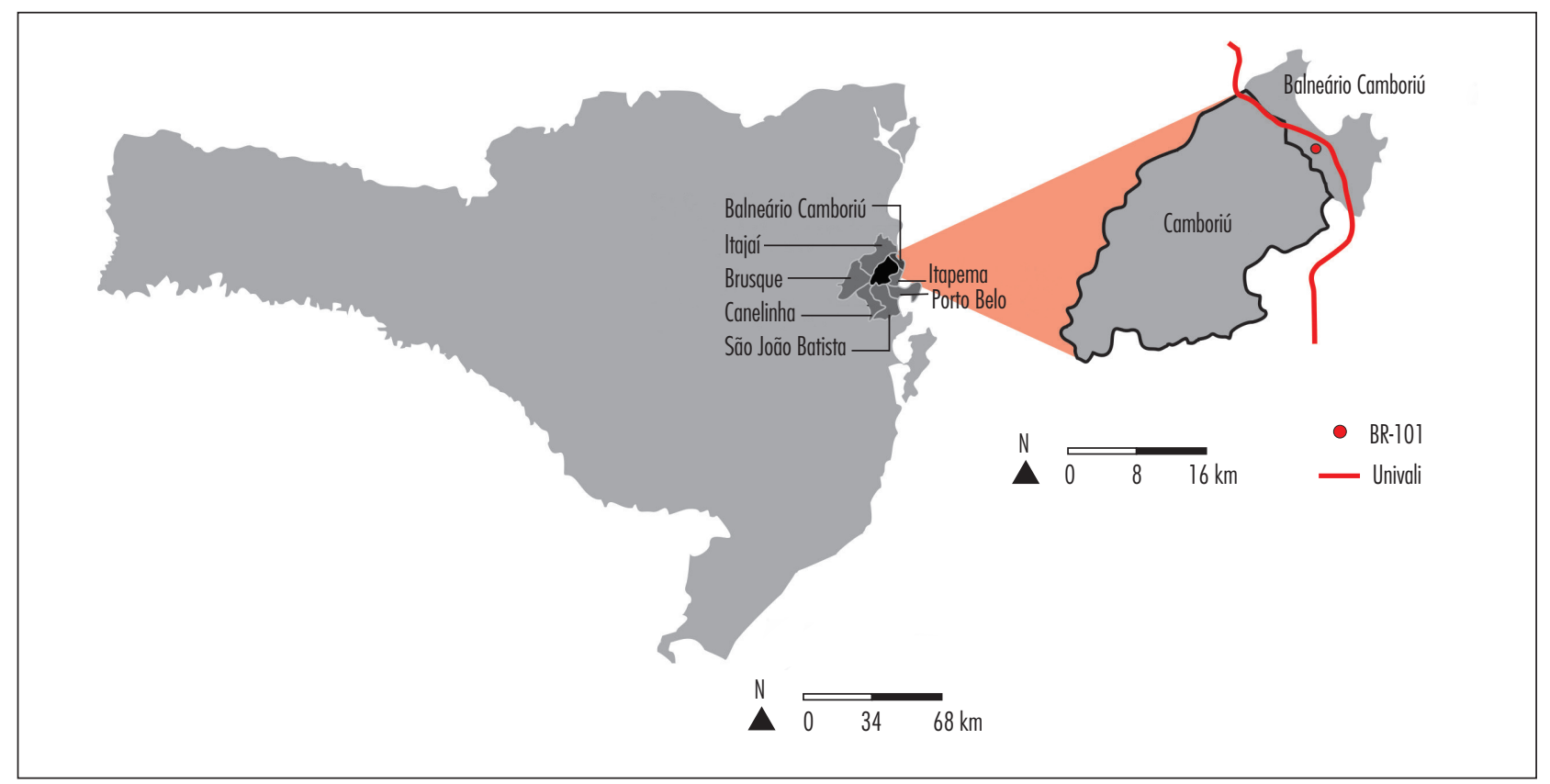

Figura 1 - Localização do município de Camboriú em Santa Catarina

Fonte: Dados da pesquisa. 
dos municípios vizinhos (especialmente Balneário Camboriú e Itajaí). Contudo, o PIB reduzido do município (em 2003 chegou a ser $1 / 4$ da média do Estado) e sua pouca diversidade econômica assinalam o baixo fluxo financeiro e evidenciam os índices de pobreza locais. No item renda per capita, o município apresenta a maior defasagem em relação aos demais municípios da região.

0 projeto de extensão e filantropia a que se refere esse artigo deu continuidade ao acompanhamento das atividades relativas ao plano diretor, iniciado em 2006/2007 tendo em vista a necessidade de sua revisão prevista na Lei Complementar n. 10/2007 (CAMBORIÚ, 2007) em seu art. 156. "A primeira revisão deste Plano Diretor deverá ser realizada em no máximo 5 (cinco anos) a contar da aprovação desta Lei e as demais revisões de acordo com o que determina a Lei 10.257/2001 - Estatuto da Cidade".

0 projeto foi realizado por quatro professores e três alunos bolsistas do curso de Arquitetura e Urbanismo da Universidade do Vale do Itajaí (Univali) durante os anos de 2011 e 2012. 0 objetivo do projeto era capacitar e prestar assessoria aos gestores públicos municipais, em especial ao Conselho da Cidade de Camboriú (ConCidade de Camboriú), órgão colegiado de caráter consultivo e deliberativo, com autonomia para tomada de decisões com representatividade de diversos setores da sociedade. A construção de uma democracia participativa no município de Camboriú caracteriza-se, portanto, por um processo de participação popular que pretende ser representativa e deliberativa.

O papel do Conselho da Cidade de Camboriú é definido na Lei Municipal n. 10/2007, que trata de sua natureza e finalidade, em consonância com a Constituição Federal de 1988 e com o Estatuto da Cidade de 2001, conforme observa-se no seu Art. 2:

o ConCidade tem por finalidade formular, estudar e propor diretrizes para implementar políticas municipais de desenvolvimento urbano, com participação social para integração das políticas de planejamento, ordenamento territorial e gestão do solo urbano, de habitação, saneamento ambiental, mobilidade e transporte urbano, em consonância com os artigos n. 182 e 183 da Constituição Federal, da Lei n. 10.257, de 10 de julho de 2001 (Estatuto da Cidade) e com a Lei
Complementar 10/2007 de 28 de dezembro de 2007 (CAMBORIÚ, 2007).

Suas competências são definidas através do regimento interno desse Conselho, incluindo desde atividades de acompanhamento e fiscalização, de convocação de audiências, conferências e assembleias, de emitir pareceres, de propor e promover debates sobre projetos de grandes impactos ambientais e/ou de vizinhança, submetendo-os à consulta popular, assim como, de atividades deliberativas para casos omissos e projetos de lei de interesse da política urbana.

O ConCidade de Camboriú, segundo definido na Lei Municipal n. 10/2007, regulamentado pelos Decretos Municipais n. 1.294/2011 e n. 1.304/2011 (CAMBORIÚ, 2011a, 2011b) que dispõem sobre a nomeação de seus membros, compõe-se de 30 membros, sendo 12 representantes do poder público municipal, dos quais 9 são do Poder Executivo e 3 do Poder Legislativo; 16 representantes da sociedade civil, sendo 3 do setor empresarial, 3 dos trabalhadores e 4 representantes de organizações não governamentais e entidades técnicas ou profissionais e 8 representantes eleitos nas localidades de planejamento.

Esse Conselho, previsto para ser criado 120 dias após a aprovação do plano diretor (CAMBORIÚ, 2007), só veio a ser criado em 2011, em função da necessidade de revisão da referida lei, prevista para acontecer em cinco anos. Sua composição foi definida pelo poder público municipal, através das premissas definidas nos artigos 43 e 45 do Estatuto da Cidade, que preveem a implantação de órgãos colegiados e sua composição buscando ampla representatividade da população e de associações representativas dos vários segmentos da comunidade. Entretanto, a mesma passa a ser questionada e revista já durante o início do processo de revisão e antes mesmo de sua constituição, tendo em vista jurisprudências do Tribunal de Contas do Estado de Santa Catarina (2003, p. 1) acerca da presença de representantes do Poder Legislativo, de maneira que, enquanto poder que deve fiscalizar as ações do Poder Executivo municipal, não poderia integrar aquele Conselho dada a sua inter-relação com o processo decisório e outras atribuições consideradas "inerentes à função executiva".

A participação desses representantes do Poder Legislativo tinha como princípio dar conhecimento do processo participativo e de elaboração e/ou 
revisão das citadas leis, assim como das audiências, reuniões, capacitações e debates, com suas resultantes no projeto de lei que seria posteriormente encaminhado à Câmara de Vereadores.

Do mesmo modo, a composição das vagas destinadas aos representantes da sociedade civil buscou permitir a participação de todas das organizações identificadas no município, assim como de seus bairros e comunidades, segundo as regiões identificadas e capacitadas durante o processo, que deveriam ser eleitos e indicados pelas associações de moradores, ongs e demais instituições. Nassuno (1997, p. 27) afirma que a representatividade da sociedade civil por meio de instituições, pressupõe, "portanto, a organização dos usuários", neste caso, da população, muitas vezes não sendo verificado na realidade e, assim, evidenciando-se dificuldade em garantir a representativa participação da população.

Houve reuniões e debates também sobre a representatividade daqueles indicados por cada região, colocando em destaque o processo de escolha destes representantes, bem como o atraso na constituição do referido Conselho, de modo que o acentuado crescimento da cidade nesse período deixou evidente a mudança das regiões identificadas por ocasião do primeiro plano, assim como a necessidade de maior número de representantes que desse conta deste aumento populacional.

Ainda assim, pode-se afirmar que durante todo o processo de elaboração da revisão do Plano diretor da cidade de Camboriú, houve abertura para participação de toda a sociedade, não somente em função da representatividade de classes expressa na composição do Conselho da Cidade, mas também nas diversas reuniões de capacitação comunitária e nas audiências públicas realizadas a cada etapa do processo de revisão do plano diretor, como representado na Figura 2.

Na Figura 2 também são apresentadas as etapas do processo de revisão do plano diretor, tendo o Conselho da Cidade estipulado um cronograma como forma de planejamento do processo. Após essa discriminação, com temas, metodologias e prazos, a serem trabalhados, houve a primeira audiência pública, realizada em 10 de agosto de 2011, para lançamento do processo de revisão do plano. A segunda etapa, denominada leitura da realidade local, foi composta pela leitura técnica e comunitária.

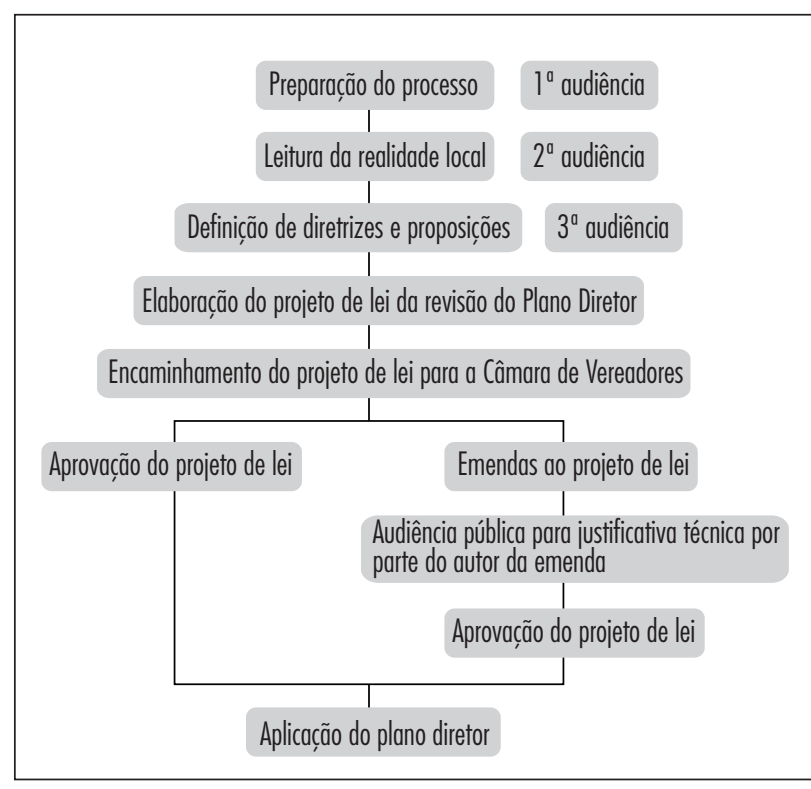

Figura 2 - Organograma do processo de revisão do plano diretor Fonte: CAMBORIÍ, 2012.

A segunda etapa foi realizada com base na divisão do município em sete setores, agrupando-se bairros da cidade com características físicas e sociais semelhantes (Figura 3). Foram realizadas reuniões para capacitação e leitura comunitária abertas a toda a comunidade, convidada à participação por meio de rádio e jornal de circulação local. Por entender que somente mediante capacitação poderá haver participação plena dos cidadãos, em busca de uma democracia participativa emancipatória, a equipe da Univali realizou encontros de capacitação popular, com objetivo de instrumentação para a participação, nos quais foram abordados aspectos relacionados ao Estatuto da Cidade, plano diretor vigente e sua estrutura, macrozoneamento, índices e instrumentos urbanísticos, assim como discussões acerca da realidade que eles poderão dar origem em cada bairro e região do município.

A leitura comunitária foi realizada a partir da experiência dos participantes (Figura 4), procurando enfatizar e valorizar sua vivência e realidade cotidiana. Com a utilização de fotografias de diversos locais do município (que foram trazidas impressas para a reunião), a população participante discutiu e apontou livremente elementos da cultura e da vivência cotidiana, identificando-se as deficiências e potencialidades de cada localidade, agrupando-as 


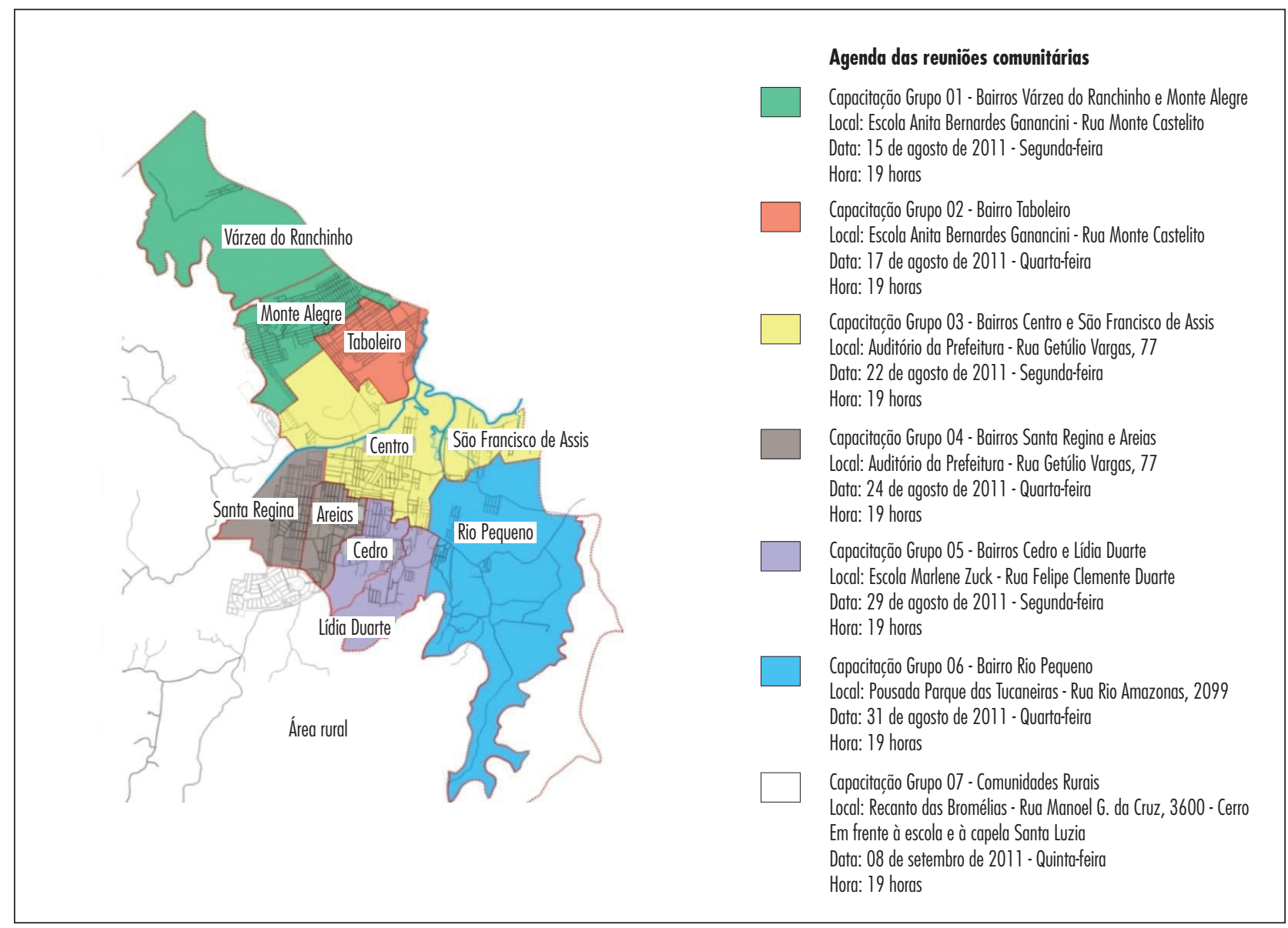

Figura 3 - Setores de planejamento e respectiva agenda de reuniões Fonte: CAMBORIÚ, 2012.

de acordo com os eixos estratégicos evidenciados no plano diretor que estava sendo revisado.

Apesar do reduzido número de participantes das reuniões referentes ao processo de revisão do plano diretor realizadas no ano de 2011, totalizando 327 participantes, cabe destacar que houve aumento significativo (aproximadamente 40\%) daquelas realizada em 2006, durante a elaboração do referido plano (Tabela 1). Isso pode ser reflexo de uma maior preocupação e atenção da população para com o que está sendo decidido e regulamentado em relação ao uso e ocupação do solo no município. Outro fator pode ter sido o maior empenho na divulgação das reuniões por parte do poder público ou também um despertar participativo após as capacitações realizadas em 2006, durante a elaboração do primeiro plano diretor.

0 números de participantes foi considerado baixo - inferior a $1 \%$ da população do município - se se levar em conta a ampla participação da população, preconizado pelo Estatuto da Cidade, mas, conforme destacado anteriormente, tem-se obtido avanços no que diz respeito a sua ampliação. Dentre as possíveis causas da pouca presença popular nas reuniões, audiências e capacitações, podem ser identificados problemas como: pouca eficiência na divulgação das agendas de atividades, seja no que diz respeito ao seu alcance ou ainda à antecedência e reforços; desconhecimento das implicações do plano diretor na cidade, no bairro e na vida da população; desconhecimento de aspectos técnicos relativos ao plano, diante da impressão de não possuir conhecimento suficiente para participar da discussão de sua própria realidade; descrença acerca da política e dos processos de planejamento, com a ideia de que a participação é perda de tempo, já que os interesses daqueles detentores do poder (seja ele político ou econômico) serão mantidos e priorizados; experiências anteriores negativas que tenham implicado na desqualificação 


\section{Centro/São Francisco}

Resultados 2011

\begin{tabular}{|c|c|}
\hline & $\begin{array}{l}\text { Data: } 22 \text { de agosto de } 2011 \\
\text { Local: Auditório da Prefeitura, Rua Getúlio Vargas, } 77 \\
\text { Participantes: } 71\end{array}$ \\
\hline 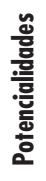 & $\begin{array}{l}\text { 1. Potencial construtivo } \\
\text { 2. Áreas comerciais/serviç̦os } \\
\text { 3. Educação } \\
\text { 4. Áreas de lazer } \\
\text { 5. Patrimônio histórico (elementos pontuais) }\end{array}$ \\
\hline פั & $\begin{array}{l}\text { 1. Falta de saneamento básico } \\
\text { 2. Falta de mobilidade urbana } \\
\text { 3. Falta de adequação de uso e ocupação do solo } \\
\text { 4. Falta de preservação ambiental (margem dos rios) } \\
\text { 5. Falta de áreas de lazer }\end{array}$ \\
\hline
\end{tabular}

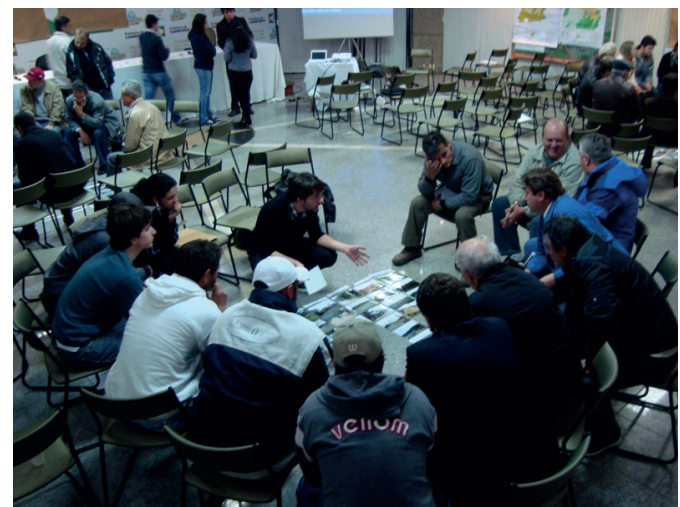

Figura 4 - Sistematização dos resultados obtidos nas leituras comunitárias Fonte: CAMBORIÚ, 2012.

Tabela 1 - Número de participantes por bairro. Plano 2006-2011

\begin{tabular}{|c|c|c|}
\hline Grupos & $\begin{array}{l}\text { Participantes: Capa- } \\
\text { citações do } 1^{\circ} \text { Plano } \\
\text { Diretor - } 2006\end{array}$ & $\begin{array}{l}\text { Participantes: Capaci- } \\
\text { tações da Revisão do } \\
\text { Plano Diretor - } 2011\end{array}$ \\
\hline Várzea do Ranchinho & 46 & \\
\hline Monte Alegre & \multirow{2}{*}{31} & \\
\hline Taboleiro & & 46 \\
\hline $\begin{array}{l}\text { Centro - São Francisco } \\
\text { de Assis }\end{array}$ & 20 & 56 \\
\hline Areias - Santa Regina & 22 & 56 \\
\hline Rio Pequeno & \multirow{2}{*}{18} & 32 \\
\hline Cedro - Lídia Duarte & & 69 \\
\hline Comunidades Rurais & 95 & 30 \\
\hline Total & 232 & 327 \\
\hline
\end{tabular}

Fonte: CAMBORIÚ, 2012.

de sua participação, ou ainda que tenham gerado expectativas não atendidas; a existência de problemas mais emergenciais a serem resolvidos dadas as condições de pobreza da maior parte da população.

Associada à leitura comunitária, houve uma reunião com os técnicos que desenvolvem projetos na cidade (engenheiros, arquitetos, agentes imobiliários), os quais também levantaram potencialidades e deficiências locais, e sugeriram objetivos, diretrizes e ações referentes a cada eixo estratégico da Lei Complementar n. 10/2007, plano diretor que estava sendo revisado. Nesse caso, acrescenta-se que, embora tenha havido essa reunião formatada de modo mais técnico, visando à participação desse grupo, verificou-se que todos aqueles agentes para os quais as modificações da referida lei pudessem implicar ganhos financeiros diretos ou indiretos, especialmente por meio de negócios imobiliários e valorização de terrenos e/ou empreendimentos, tiveram ampla participação em todas as reuniões e etapas desenvolvidas, ao contrário do observado quanto à participação da população. Por diversas vezes, esses interesses se deixam transparecer através da pressão e de perguntas sobre o momento em que a lei do zoneamento seria revisada, assim como na formação de ideais sobre a cidade de Camboriú, fundamentadas nas características da cidade vizinha de Balneário Camboriú, colocando-a quase como objetivo a ser alcançado.

Como forma de garantir uma leitura da realidade local completa, além da leitura comunitária, foi realizada também a leitura dos técnicos que compõem diversas secretarias do poder público municipal sobre as potencialidades e deficiências locais. 
O resultado foi um documento atualizado e remodelado com relação ao de 2006, que compila o levantamento de dados e leitura da cidade, com base nos dos diversos subsistemas do município, expressando-se as leituras comunitária e dos técnicos municipais.

Após esse processo de leitura da realidade local, foi realizada a $2^{\text {a }}$ Audiência Pública, buscando mais uma forma de garantir a gestão democrática da cidade, com a apresentação da leitura da realidade local.

Em continuação ao processo foram realizadas seis reuniões do Conselho da Cidade abertas à população, para revisar a Lei Complementar n. 10/2007 (CAMBORIÚ, 2007). Focou-se nos objetivos, diretrizes e ações de cada eixo estratégico, bem como no macrozoneamento, instrumentos urbanísticos e gestão. Após essa etapa, também houve a $3^{\text {a }}$ Audiência Pública, finalizando-se o processo de revisão do plano diretor.

Todo esse processo envolveu diretamente 1.119 participações. Não foram consideradas como participantes, pois um mesmo sujeito pode ter participado em distintos momentos ao longo do processo.

\section{A limitação da democracia deliberativa e as possibilidades da teoria emancipatória}

A participação popular depende da vontade natural (bios polítik) de cada cidadão. A legitimidade da participação provém de atitudes distintas: alguns cidadãos agem em prol da participação, por isso reservam tempo e energia para se encorajar, enquanto a maioria não considera necessário investir tempo neste assunto, porque, afinal, não há valorização dessa participação voluntária (MEMMI apud GAGLIETTI, 2003).

O que se identificou a partir da experiência vivenciada no projeto de extensão e filantropia realizado pela Univali em Camboriú é que, apesar de toda a abertura dada à participação comunitária no processo de planejamento, não há uma busca por parte da comunidade. 0 que ocorre é um chamamento, por parte do Estado, para a participação no Conselho da Cidade dos diversos segmentos representativos da sociedade, na construção da leitura comunitária, na revisão da lei do plano diretor e nas audiências públicas.

É nesse ponto que se dá a crítica ao modelo deliberativo: "[...] os sistemas deliberativos têm sido estruturas competitivas controladas por grupos de poder e mercado" (OLIVEIRA FILHO, 2009, p. 69), há um "monopólio da comunicação" da política, de modo que o desequilíbrio da comunicação é mais uma causa do desinteresse político e da debilidade da participação popular (BOURDIEU apud OLIVEIRA FILHO, 2009). Nesse sistema democrático, existe uma luta entre os cidadãos que possuem e os que não possuem o "código". Assim, estes últimos são automaticamente excluídos da política. Esse código pode ser uma posição social mais importante ou até a própria dificuldade no entendimento da lei e em sua aplicação.

Em Camboriú, durante a etapa de leitura comunitária, que ocorreu após a primeira audiência pública, na qual foram realizadas sete capacitações comunitárias, houve um número maior de representantes da comunidade, se comparado com a quantidade de pessoas nas demais audiências públicas. As reuniões propiciaram um espaço de valorização da opinião do cidadão, pelo fato de serem realizadas nos próprios bairros da cidade e também por gerarem um espaço de discussão focado na opinião e vivência dos participantes. Essa é uma atitude de inclusão, mas que ainda não atua de forma paralela com as decisões do Estado.

[...] o que tem havido é a ampliação dos canais de participação como obrigatoriedade na realização de audiências e consultas públicas e o estabelecimento dos sistemas de conselhos consultivos e deliberativos [...], porém o fato de existirem instâncias formais de participação popular não garante a qualidade desta participação (OLIVEIRA FILHO, 2009, p. 20).

Essa ampliação dos canais de participação sem que se reverta em qualidade pode ser verificada, por exemplo, no fato de que ela não possui poder de decisão, tal como afirmam Limonad e Barbosa (2003, p. 4):

[...] a participação da população serve mais para a validação e legitimação sob o selo democrático de práticas definidas como desejáveis por setores hegemônicos. Pois, como sóe acontecer, esta participação é passível de ocorrer ao nível das decisões táticas - referentes à consulta relativa a implementação de ações localizadas - como é o caso dos 
Estudos de Impacto de Vizinhança e Operações Consorciadas. Porém, esta participação não se faz ao nível das decisões políticas e estratégicas - nível em que é tomada a decisão de implementação destas operações. [...] Ao que tudo indica, portanto, a participação no processo de planejamento permanece limitada e subordinada aos interesses do governo vigente ao nível local [...].

O conceito de participação emancipatória defende a "libertação" da participação popular da regência do Estado, segundo Oliveira Filho (2009). 0 referido autor defende uma expansão dos espaços democráticos formais. Hoje esses espaços são Conselhos por meio de eleições, regra da maioria e acordos coletivos. Ele propõe uma expansão para espaços como trabalho, família, escola, associações, universidades e mundial.

A vida política e a privada, separadas na sociedade grega, segundo Arendt (2005), agora se propõe unir, visto que o homem como um todo, incluindo suas ações, é dependente da vida em comunidade, e isso é política.

Esse é um modelo complexo, porque requer uma mudança na política como também no direito, gerando uma transformação social em que a inclusão política é feita através dos cidadãos e do Estado como um processo estimulado, e o modelo de decisão não se dá mais por meio de Conselhos consultivos ou deliberativos, mas sim um orçamento participativo, com estímulo ao associacionismo e as organização sociais.

Nesse modelo, sim, a ideia de MacPherson (1977) pode ocorrer: um sistema representativo, diante da quantidade de habitantes de nossas cidades, sem que seja necessariamente concorrencial e excludente, mas que atue de forma horizontal com os sistemas políticos atuais na tomada de decisões, a partir de uma força maior no âmbito da comunidade.

\section{Considerações finais: a Universidade como instrumento decodificador do sistema atual e abrindo portas a uma nova estrutura emancipatória}

A partir dos resultados obtidos nas reuniões de capacitações e leitura comunitária realizadas pela equipe da Univali, com o projeto de extensão e filantropia no município de Camboriú, percebeu-se a importância das instituições de ensino na construção desse processo de revisão do plano diretor. Além de garantir legitimidade ao processo, impedindo que se concentre somente nas mãos do Estado, as instituições de Ensino Superior podem oferecer o suporte técnico e teórico que gera discussão e melhor entendimento da realidade local, provocando a crítica, o envolvimento e a ampla comunicação política.

Nesse ponto, a Universidade pode desempenhar um papel fundamental na superação do desequilíbrio da comunicação entre aqueles detentores do "código" e os que não o possuem (BOURDIEU, 2003 apud OLIVEIRA FILHO, 2009), ainda que haja limitação dessa atuação no que tange à disseminação do conhecimento técnico enquanto instrumental ampliador da consciência, percepção e entendimento daqueles aspectos reais, legais e sua discussão.

Portanto, a Universidade apresenta-se, nesse caso, como um "decodificador" que auxilia na retomada da comunicação entre o Estado e a sociedade, auxiliando também na superação dos desafios para a efetiva participação. Esses desafios são a improvisação na referida participação, a transferência de responsabilidade da esfera estatal para parceiros não estatais ou outros envolvidos e, por último, a possibilidade do processo de participação ser manipulado (MORAES et al., 2010).

Além de poder ser um articulador entre o Estado e a sociedade, as instituições de Ensino Superior podem capacitar e "equipar" teoricamente e tecnicamente os diversos grupos da sociedade, para que eles tenham condições de construir um programa de ação diante da oportunidade de decisão, avançando de um modelo deliberativo de participação para a construção de um novo modelo que favoreça a estrutura emancipatória de participação.

\section{Referências}

ARENDT, H. A condição humana. Trad. Roberto

Raposo. Rio de Janeiro: Forense Universitária, 2005.

ARISTÓTELES. A Política. Trad. Torrieri Guimarães. São Paulo: Martin Claret, 2005. 
BACK, C. C. Os limites e contradições da aplicação dos instrumentos. 2004. 241 f. Dissertação (Mestrado em Engenharia Ambiental) - Universidade Regional de Blumenau, Blumenau, 2004.

BERNARDI, J. L. Funções sociais da cidade: conceitos e instrumentos. 2006. 137 f. Dissertação (Mestrado em Gestão Urbana) - Pontifícia Universidade Católica do Paraná, Curitiba, 2006.

BOSCHI, R. R. Descentralização, clientelismo e capital social na governança urbana: comparando Belo Horizonte e Salvador. Revista Dados, v. 42, n. 4, p. 655-690, 1999.

BRAGA, R. Plano diretor municipal: três questões para discussão. Caderno do Departamento de Planejamento, v. 1, n. 1, p. 15-20, 1995.

BRASIL. Constituição (1988). Constituição da República Federativa do Brasil. Brasília: Senado Federal, 1988. Disponível em: <http://www.planalto.gov.br/ccivil_03/ constituicao/constituicao.htm>. Acesso em: 3 jan. 2013.

BRASIL. Lei n. 10.257, de 10 de julho de 2001. Regulamenta os art. 182 e 183 da Constituição Federal, estabelece diretrizes gerais da política urbana e dá outras providências. Diário Oficial [da] República Federativa do Brasil, Brasília, DF, 11 jul. 2001. Disponível em: <http://www. planalto.gov.br/ccivil_03/leis/LEIS_2001/L10257.htm>. Acesso em: 3 jan. 2013.

BRASIL. Decreto n. 4.665, de 3 de abril de 2003. Aprova a Estrutura Regimental e o Quadro Demonstrativo dos Cargos em Comissão do Ministério das Cidades, e dá outras providências. Diário Oficial [da] República Federativa do Brasil, Brasília, DF, 4 abr. 2003. Disponível em: <http:// www2.camara.leg.br/legin/fed/decret/2003/decreto-4665-3-abril-2003-496239-publicacaooriginal-1-pe. html>. Acesso em: 2 nov. 2012.

BRASIL. Decreto n. 5.790, de 25 de maio de 2006. Dispõe sobre a composição, estruturação, competências e funcionamento do Conselho das Cidades - ConCidades, e dá outras providências. Diário Oficial [da] República Federativa do Brasil, Brasília, DF, 26 maio 2006. Disponível em:<http:// www.planalto.gov.br/ccivil_03/_ato2004-2006/2006/ Decreto/D5790.htm>. Acesso em: 3 jan. 2013.
CAMBORIÚ (Prefeitura municipal). Lei Complementar n. 10, de 28 de dezembro de 2007. Institui o Plano Diretor de Desenvolvimento Territorial de Camboriú PDDTC. Camboriú, SC, 28 dez. 2007. Disponível em: $<$ www.leismunicipais.com.br/a/sc/c/camboriu/lei-complementar/2007/1/10/lei-complementar-n-10-2007-institui-o-plano-diretor-de-desenvolvimento-territorial-de-camboriu-pddtc-2007-12-28.html>. Acesso em: 12 nov. 2012.

CAMBORIÚ (Prefeitura municipal). Decreto no 1294, de 21 de julho de 2011. Dispõe sobre a nomeação dos membros do Conselho Municipal da Cidade. Camboriú, SC, 21 jul. 2011a. Disponível em: <www.leismunicipais.com. br/a/sc/c/camboriu/decreto/2011/129/1294/decreto-n-1294-2011-dispoe-sobre-a-nomeacao-dos-membros-do-conselho-municipal-da-cidade-2013-08-28.html>. Acesso em: 12 nov. 2012.

CAMBORIÚ (Prefeitura municipal). Decreto n. 1304, de 3 de agosto de 2011. Autoriza o Conselho Municipal da Cidade a propor, opinar e monitorar a 1‥ Revisão do Plano Diretor de Desenvolvimento Territorial de Camboriú e dá outras providências. Camboriú, SC, 3 ago. 2011b. Disponível em: <www.leismunicipais. com.br/a/sc/c/camboriu/decreto/2011/130/1304/ decreto-n-1304-2011-autoriza-o-conselho-municipal-da-cidade-a-propor-opinar-e-monitorar-a-1-revisao-do-plano-diretor-de-desenvolvimento-territorial-de-camboriu-e-da-outras-providencias-2011-08-03.html>. Acesso em: 12 nov. 2012.

CAMBORIÚ (Prefeitura municipal). Leitura da Cidade. Camboriú: Secretaria Municipal de Planejamento Urbano, 2012.

CHOAY, F. 0 urbanismo: utopias e realidades - uma antologia. São Paulo: Editora Perspectiva, 2000.

DEL RIO, V.; GALLO, H. O legado do urbanismo moderno no Brasil. Paradigma realizado ou projeto inacabado? Arquitextos, v. 1, n. 6, nov. 2000. Disponível em: $<$ http://www.vitruvius.com.br/revistas/read/arquitextos/01.006/958>. Acesso em: 12 jan. 2012.

FÓRUM NACIONAL DE REFORMA URBANA. Função social da propriedade. 2012. Disponível em: <http:// www.forumreformaurbana.org.br/index.php/plataforma-fnru/a-funcao-social-da-propriedade.html $>$. Acesso em: 10 dez. 2012. 
FREIRE, P.; CYMBALISTA, R.; NAKAHIMA, R. O Plano Diretor de Sorocaba: um olhar sobre os atores e a auto-aplicabilidade dos instrumentos urbanísticos. São Paulo: Polis Publicações, 2009.

GAGLIETTI, M. J. PT: ambivalências de uma militância. Porto Alegre: Dacasa, 2003.

HABERMAS, J. A inclusão do outro: estudos de teoria política. São Paulo: Edições Loyola, 2002.

HEALEY, P. Collaborative planning: shaping places in fragmented societies. London: Macmillan, 1997.

HOLSTON, J. A cidade modernista: uma crítica de Brasília e sua utopia. São Paulo: Companhia das Letras, 1993.

INSTITUTO BRASILEIRO DE GEOGRAFIA E ESTATÍSTICA — IBGE. Censo demográfico 2010. 2010. Disponível em: <http://www.censo2010.ibge.gov.br>. Acesso em: $10 \mathrm{fev}$. 2012.

KLINK, J. Planejamento, estratégia local e complexidade: uma reinterpretação do legado do projeto Eixo Tamanduatehy (Santo André). Revista Brasileira de Estudos Urbanos e Regionais, v. 13, n. 1, maio 2011. Disponível em: <http://www.anpur.org.br/inicio/images/ revistas/rev_ANPUR_v13_n1.pdf\#page=121>. Acesso em: 24 abr. 2013.

LIMONAD, E.; BARBOSA, J. L. Entre o ideal e o real rumo à sociedade urbana: algumas considerações sobre o "Estatuto da Cidade". Geousp, n. 13, 2003. Disponível em: <http://www.geografia.fflch.usp.br/publicacoes/Geousp/ Geousp13/Geousp13_Limonad_Barbosa.htm>. Acesso em: 27 abr. 2013.

MACPHERSON, C. B. A democracia liberal: origens e evolução. Rio de Janeiro: Zahar Editores, 1977.

MARICATO, E. As idéias fora do lugar e o lugar fora das ideias - planejamento urbano no Brasil. In: ARANTES, 0.; VAINER, C.; MARICATO, E. A cidade do pensamento único: desmanchando consensos. Petrópolis: Vozes, 2000. p. 121-192.

MELUCCI, A. The symbolic challenge of contemporary movements. Social Research, v. 52, n. 4, p. 788-816, 1985.
MINISTÉRIO DAS CIDADES. Composição do ConCidade Gestão 2011/2013. 2012. Disponível em: <http://www. cidades.gov.br/index.php/composicao-concidades $>$. Acesso em: 1ํo out. 2012.

MORAES, S. et al. Capacitação e mobilização: a perspectiva da participação cidadã no Plano Diretor de Balneário Camboriú (SC). Revista de Gestão Costeira Integrada, v. 10, n. 4, p. 567-587, dez. 2010.

MUNIZ, C. R., FERREIRA, V. R. S., MIGLIORINI, V. L. B. 0 Estatuto da cidade como instrumento de gestão urbana sistêmica. 2008. Disponível em: <http:// www.iau.usp.br/pesquisa/grupos/e-urb/Relatorios/ RelTecCont2009_Estatuto_da_Cidade.pdf>. Acesso em: 10 nov. 2012.

NASSUNO, M. Organização dos usuários, participação na gestão e controle das organizações sociais. Revista do Serviço Público, v. 48, n. 1, jan./abr. 1997.

NEGROMONTE, M. Apresentação. In: SANTOS Jr., O. A.; MONTANDON, D. T. (Org.). Os planos diretores municipais pós-estatuto da cidade: balanço crítico e perspectivas. Rio de Janeiro: Editora Letra Capital; Observatório das Cidades; IPPUR; UFRJ, 2011. p. 11-12

OLIVEIRA FILHO, J. T. A participação popular no planejamento urbano: a experiência do Plano Diretor de Porto Alegre. 2009. 332 f. Tese (Doutorado em Planejamento Urbano e Regional) - Universidade Federal do Rio Grande do Sul, Porto Alegre, 2009.

RANDOLPH, R. Do planejamento colaborativo ao planejamento "subversivo": reflexões sobre limitações e potencialidades de planos diretores no Brasil. Revista electrónica de geografía y ciencias sociales, v. 11, n. 245, ago. 2007. Disponível em: <http://www.ub.edu/geocrit/sn/ sn-24517.htm>. Acesso em: 26 abr. 2013.

ROLNIK, R. A construção de uma política fundiária e de planejamento urbano para o país - avanços e desafios. Boletim de Políticas Sociais, n. 12, p. 199-209, fev. 2006.

SANTOS, B. S. Reinventar a democracia e promover a emancipação social. São Paulo: Cortez, 2006.

SANTOS, B. S. (Org.). Democratizar a democracia: os caminhos da democracia participativa. Rio de Janeiro: Civilização Brasileira, 2002. 
SANTOS Jr., O. A.; SILVA, R. H.; SANT'ANA, M. C. Introdução. In: SANTOS JUNIOR, O. A.; MONTANDON, D. T. (Org.). Os planos diretores municipais pós-estatuto da cidade: balanço crítico e perspectivas. Rio de Janeiro: Editora Letra Capital/Observatório das Cidades; IPPUR; UFRJ, 2011. p. $13-26$.

SANTOS Jr., O. A.; MONTANDON, D. T. (Org.). Os planos diretores municipais pós-estatuto da cidade: balanço crítico e perspectivas. Rio de Janeiro: Editora Letra Capital/Observatório das Cidades; IPPUR; UFRJ, 2011.

SILVA, M. K. Construção da participação popular: análise comparativa de processos de participação social na discussão pública do orçamento em municípios da Região Metropolitana de Porto Alegre (RS). 2001. 295 f. Tese (Doutorado em Sociologia) - Universidade Federal do Rio Grande do Sul, 2001. Disponível em: <https://www.repositorioceme.ufrgs.br/bitstream/handle/10183/2169/000315369.pdf?sequence=1 >. Acesso em: 23 abr. 2013.

SOUZA, M. L. Desenvolvimento urbano: a problemática renovação de um "conceito" problema. Revista Território, v. 3, n. 5, p. 5-29, jul./dez. 1998.

TORRES, N. R. Planejamento numa sociedade em rede: práticas de planejamento colaborativo no Brasil. Cadernos Metrópole, v. 11, n. 22, p. 571-591, jul./dez. 2009. Disponível em: <http://revistas.pucsp.br/index. php/metropole/article/view/5948>. Acesso em: 25 abr. 2013.
TRIBUNAL DE CONTAS DO ESTADO DE SANTA CATARINA. Prejulgado 1425. Processo CON-03/03243864, de 02 out 2003. 2003. Disponível em: <http://www.tce.sc.gov. br/web/menu/decisoes>. Acesso em: 24 abr. 2013.

ULTRAMARI, C.; FIRKOWSKI, O. L. Sobre mudanças e continuidades na gestão urbana brasileira. Revista Mercator, v. 11, n. 24, p. 73-88, jan./abr. 2012.

VALLA, V. V. Sobre participação popular: uma questão de perspectiva. Cadernos de Saúde Pública, n. 14 (Sup. 2), p. 7-18, 1998. Disponível em: <http://www.scielosp.org/ pdf/csp/v14s2/1322.pdf>. Acesso em: 23 abr. 2013.

VILLAÇA, F. Dilemas do plano diretor. 1998. Disponível em: <http://www.flaviovillaca.arq.br/pdf/cepam2.pdf>. Acesso em: 20 nov. 2012.

VILLAÇA, F. As ilusões do plano diretor. 2005. Disponível em: <http://www.flaviovillaca.arq.br/pdf/ilusao_ pd.pdf>. Acesso em: 20 nov. 2012.

Recebido: 30/04/2013

Received: 04/30/2013

Aprovado: $13 / 05 / 2013$

Approved: 05/13/2013 